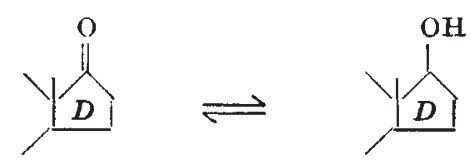

We have observed that another trichomonad ( $T$. foetus) also brings about specific transformations of this type.

The interconversion of keto- and hydroxy-steroids occurs in a variety of mammalian tissues*. In many instances, bacteria ${ }^{5}$, yeasts ${ }^{6}$, moulds ${ }^{7}$ and actinomycetes $^{8}$ have also been reported to affect the oxygenation of $\mathrm{C}_{18}$ and $\mathrm{C}_{19}$ steroids in the 17 - as well as the 3-positions. Our findings show that reactions of this type can also be carried out by Protozoa.

Further work will be published elsewhere. Acknowledgment is made to Mr. L. M. Reineke and his associates for the paper chromatographic analyses, and to Dr. J. L. Johnson and Mrs. G. S. Fonken for the infra-red spectrographic data.

OLDRICH K. SEBEK

RHODA M. MrChaELS

Research Laboratories,

The Upjohn Company,

Kalamazoo, Michigan. Nov. 2.

${ }^{1}$ Hanc, O., and Riedl-Tưmová, E., Pharmazie, 9, 877 (1954). Wettstein, A., Experientia, 11, 465 (1955). Eppstein, S. H., Melster P. D., Murray, H. C., and Peterson, D. H., in "Vitamins an Hormones", 14, 359 (Academic Press, New York, N.Y., 1956).

${ }^{2}$ Cr. Rees, C. W., Bozicewich, J., Reardon, L. V., and Daft, F. S. A mer. J. Troo, Med., 24, 189 (1944). Conner, R. L., and van Wagtendonk, w. J., J. Cen. Microbiol., 12, 31 (1955).' Vishniak, H. S., J. Gen. Microbiol., 12, 464 (1955).

${ }^{3}$ Reineke, L. M., Anal. Chem., 28, 1853 (1956).

- Cf. Lieberman, S., and Teich, S., Pharmacol. Rev., 5, 285 (1953).

'Mamoli, X., Koch, R., and Teschen, H., Z. xhysiol. Chem., 261, 287 (1939). Cf. Arnaudi, C., Applied Microbiol., 2, 274 (1954).

'Mamoli, L, and Vercellone, A., Z. physiol. Chem., 245, 93 (1937). Wettstein, A., Helv. Chim. Acta, 22, 250 (1939), Butenandt, A., Dan-
nenberg, H., and Suranyi, L. A., Ber., 73, 818 (1940).

'Cf. Vischer, E., and Wettstein, A., Experientia, 9, 371 (1953).

${ }^{8}$ Turfitt, G. E., Biochem. J., 40, 79 (1946); 42, 376 (1948). Heusghem, C., and Welsch, M., Bull. Soc. Chim. Biol., 31, 282 (1949).

\section{Isolation of Melanin Granules}

The study of melanin granules is of both commercial and academic importance in the investigation of the pigmentation and bleaching of animal fibres. A means of separation of the granules from the keratin matrix which leaves them morphologically and chemically unaffected is therefore desirable. The methods of isolation which have so far been used consist in dissolving the keratinous material either by acid or alkaline hydrolysis, or by treatment with a mixture of phenol hydrate and thioglycollic acid. Of these, the last ${ }^{1,2}$ appears to be the most satis. factory, because it leaves the granules undamaged. It is, however, extremely laborious, involving refluxing of the protein substance for twenty-four hours, after which the resultant suspension is centrifuged for $10 \mathrm{hr}$.

By refluxing melanin-containing protein with 60 per cent $\mathrm{w} / \mathrm{v}$ hydrazine/absolute alcohol solution for $2 \mathrm{hr}$., using a liquor ratio of $50: 1$, it has been found possible to isolate the pigment granules. The protein is converted into hydrazides of low molecular weight ${ }^{3,4}$ and any undispersed matter is filtered out on a coarse filter paper, through which the granules pass. The suspension is centrifuged for $2 \mathrm{hr}$. at $2,000 \mathrm{~g}$, the supernatant liquor is decanted off and the residual granules are washed three times with distilled water.

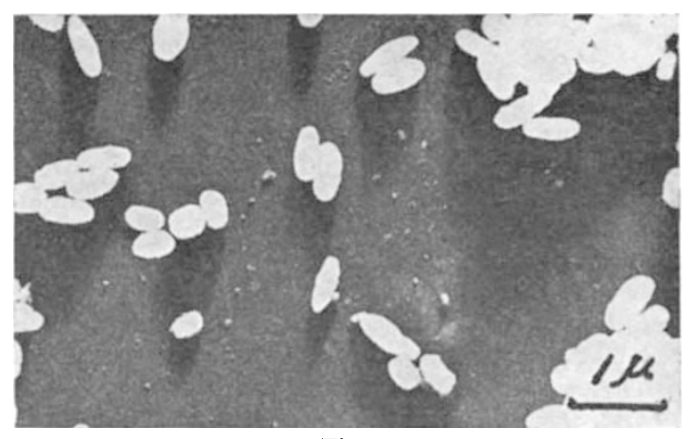

Fig. 1

The accompanying electron micrograph (Fig. 1), for which we are indebted to Dr. J. Sikorski, shows granules which have been isolated by the above treatment from dark-brown Welsh mountain wool. As may be seen, they appear to be morphologically unaffected, though in this instance they were refluxed for $4 \mathrm{hr}$. Even after digestion for $2 \mathrm{hr}$., however, the granules are quite clean, and no advantage is to be gained by the longer treatment.

Textile Chemistry Laboratory,

A. FrLson

J. HOPE

Department of Textile Industries,

University, Leeds. Oct. 26.

${ }^{1}$ Laxer, Sikorski, Whewell and Woods, Biochim. Biophys. Acta, 15, 174 (1954).

2 Hope, Sikorski and Whewell, Proc. First European Regional Conference on Electron Microscopy, Stockholm 1956 (in the press).

${ }^{3}$ Akabori, Ohno and Norita, Bull. Soc. Chim. Japan, 25 (3), 214 (1952).

4 Blackburn and Lee, J. Text. Inst., 45, T148 (1954).

\section{Interatomic Bonding in Manganese Trifluoride}

The monoclinic unit cell of manganese trifluoride has dimensions $a, 8.904 \pm 0.003 ; b, 5.037 \pm 0.002$; $c, 13.448 \pm 0.005$ A.; $\beta, 92 \cdot 74 \pm 0.04^{\circ}$, and contains twelve manganese and thirty-six fluorine atoms in general and special positions ${ }^{1}$ of space group $C 2 / c-C^{6}{ }_{2 h}$. The structure is pseudo-rhombohedral, and since the packing of fluorine atoms is midway between close-packed hexagonal and a $\mathrm{ReO}_{3}$ type defective cubic close-packing, it is classified as a $\mathbf{V F}_{3}$-type transition-element trifluoride ${ }^{3} \mathbf{M n F}_{8}$ octahedra are joined by sharing corners, and the lower symmetry of the structure, in comparison with other trifluorides of the first long period, results from the unusual occurrence of three different $\mathrm{Mn}-\mathrm{F}$ bondlengths $(2 \cdot 09,1.91$ and 1.79 A.) within erch octahedron.

Crystal-field (or ligand-field) theory ${ }^{3}$ has been applied recently by Harris, Nyholm and Stephenson 4 to explain the abnormally long $\mathrm{Pd}-\mathrm{I}$ bonds observed in the distorted octahedral complex $\mathrm{Pd}$ (diarsine) ${ }_{2} \mathrm{I}_{\mathbf{2}}$. A similar explanation is now offered for the unsymmetrical bonding in manganese trifluoride.

The magnetic moment ${ }^{5}$ of 4.9 Bohr magnetons implies that there are four unpaired electrons in the $3 d$ shell of the Mn(III) atom. Three of these occupy the $d_{\varepsilon}$ orbitals, and the remaining electron is probably in a $3 d_{z^{2}}$ orbital. The empty $3 d_{\left(x^{2}-y^{3}\right)}$ orbital points in the direction of four fluorine ions and together with the $4 s$ and two $4 p$ orbitals forms four hybrid $d s p^{2}$ bonds directed towards the corners of a square. The three singly occupied $d_{\varepsilon}$ orbitals offer no repulsion 